Revista de

Contabilidade e

Organizações

www.rco.usp.br
DOI: http://dx.doi.org/10.11606/issn.1982-6486.rco.2019.148176
Journal of

Accounting and

Organizations

\title{
Análise do relatório de guidance em empresas investigadas pela Polícia Federal: exame sob a perspectiva do gerenciamento de impressões
}

Analysis of the guidance report in companies investigated by the Federal Police: examination from the perspective of impression management

Vagner Alves Arantes ${ }^{\mathrm{a}}$; Ivonaldo Brandani Gusmão ${ }^{\mathrm{b}}$ : Mayla Cristina Costa

${ }^{a}$ Universidade Federal de Viçosa

${ }^{b}$ Universidade Estadual do Centro-Oeste

'Universidade Federal do Paraná

Palavras-chave

Guidance.

Gerenciamento de Impressões.

Polícia Federal.
Keywords

Guidance.

Impression Management.

Federal Police.

\section{Resumo}

Analisamos se as investigações de fraudes feitas pela Polícia Federal em três operações recentes geraram algum efeito na divulgação de informações prospectivas das empresas denunciadas. As operações Carne Fraca, Lava Jato e Zelotes poderiam alterar o gerenciamento de impressões nas informações prospectivas reportadas pelas empresas. Ponderamos o conteúdo dos chamados relatórios de guidance das empresas investigadas nessas operações entre 2010 a 2017, incluindo informações financeiras, operacionais e de investimentos. O período de análise coincide com o início da divulgação do relatório anual de guidance em 2010 pelas empresas listadas na Brasil Bolsa Balcão (B3). Os resultados mostram que o padrão de divulgação (tom mais positivo ou mais negativo) varia entre as empresas investigadas, indo desde uma rápida retomada do otimismo, até a descontinuidade do relatório.

\begin{abstract}
We analyzed whether the fraud investigations by the Brazilian Federal Police on the Carne Fraca, Lava Jato and Zelotes operations generated any effects on the reporting of by the implicated firms. The Carne Fraca, Lava Jato and Zelotes operations may alter the impressions management on prospective information disclosed by those firms. Our analysis covered the content of guidance reports from implicated firms between 2010 and 2017 on financial, operational and investment information. The period of analysis coincides with the beginning of the annual guidance reporting from 2010 by the companies listed in Brasil Bolsa Balcão stock market. The results show the reporting pattern (positive or negative tone) varies according the implicated firm, from an immediate positive tone recovering up to the reporting interruption.
\end{abstract}

\section{Implicações práticas}

Considera-se que os órgãos reguladores podem utilizar-se dos resultados auferidos para a implementação de softwares automatizados, que sejam capazes de captar a alternância do padrão de divulgação. Desta forma, criam-se mecanismos de enforcement para que penalidades sejam impostas às organizações investigadas que intencionalmente pretendam ocultar informações, enquanto investidores e analistas cientes dos resultados podem exercer pressão para que mudanças sejam realizadas.

Copyright (C) 2019 FEA-RP/USP. Todos os direitos reservados

\section{INTRODUÇÃO}

A Polícia Federal deflagrou nos últimos anos no Brasil operações com repercussão internacional que investigavam denúncias de corrupção, lavagem de dinheiro e sonegação fiscal envolvendo tanto empresas de capital aberto e fechado, quanto agentes públicos. Essas investigações ganharam a mídia nacional e internacional, principalmente a partir de 2014. Os jornais como Folha de São Paulo, Estadão, The Guardian, The Economist, The Intercept, dedicaram manchetes às investigações, bem como se mantiveram atentos à deflagração das fases dessas operações. O envolvimento da mídia e o apoio da população acabou legitimando as operações, aumentando a exposição dos fatos apurados à população e aos stakeholders.

Autor Correspondente: Tel. (41)3855-9344

E-mail: vagnerufv@gmail.com (V. A. Arantes); ivonaldo@unicentro.br (I. B. Gusmão); mayla.c.costa@gmail.com (M. C. Costa)

Universidade Federal de Viçosa. Campus Universitário - Rodovia MG-230 Km 7 - Rio Paranaíba/MG - 38810000, Brasil 
Entre as diferentes operações deflagradas, a presente pesquisa aborda as operações Lava Jato, Zelotes e a Carne Fraca, que juntas apontaram irregularidades em mais de 100 empresas de capital aberto e fechado (Araújo, Rodrigues, Monte-Mor, \& Correia, 2018; Partyka, Lana, \& Alberton, 2018; Schmidt, Martins, Santos, \& Kloeckner, 2018). A operação Lava Jato, deflagrada em 2014, partiu de denúncias de corrupção e lavagem de dinheiro na Petrobras S.A. envolvendo empreiteiros e agentes políticos. A operação Zelotes, iniciada em 2015, analisou a sonegação fiscal de empresas que negociavam isenções e resultados de processos junto ao Conselho de Administração de Recursos Fiscais (CARF) do Ministério da Fazenda. Por fim, a operação Carne Fraca em 2017 apontou o uso de produtos químicos e outras formas de maquiagem em lotes de carnes vencidas, envolvendo agentes de fiscalização sanitária e as empresas produtoras.

Essas operações resultaram em ganhos indevidos às organizações, com potencial impacto em produção e vendas, no nível de investimentos e no resultado financeiro. Tais potenciais efeitos seriam decorrentes da lavagem de dinheiro e a formação de cartel (Lava Jato), da sonegação fiscal (Zelotes), ou da adulteração de produtos (Carne Fraca). Apesar de não esperarmos que potenciais implicações e riscos dessas operações estivessem presentes nos relatórios antes das denúncias, ganhos indevidos poderiam estar implícitos nas expectativas de resultados. Com as denúncias, o conteúdo dos relatórios pode ter sido afetado, justificando algumas ações e correção de conduta estratégica. Isso seria mostrado pela mudança de comportamento da política de divulgação das empresas investigadas. Tal mudança poderia ser motivada pelas consequências jurídicas e penais impostas às organizações e aos agentes envolvidos.

Estudos anteriores analisaram a relação entre as operações da Polícia Federal e os demonstrativos contábeis dessas organizações (Araújo et al., 2018; D’Souza, Aragão, \& De Luca, 2018; Medeiros \& Silveira, 2017; Partyka et al., 2018; Schmidt et al., 2018). No entanto, ainda são restritas as pesquisas que apontam como as ações de corrupção, lavagem de dinheiro, ou sonegação fiscal impactam as informações prospectivas elaboradas pelas empresas. Assim, aqui analisamos se as denúncias de investigações da Polícia Federal afetam as informações prospectivas de empresas investigadas. Para isso, aplicamos a literatura de gerenciamento de impressões, e fazemos uma análise de conteúdo do relatório de guidance divulgados por cinco empresas investigadas (Petrobras S.A.; Bradesco S.A.; Marcopolo S.A, Santander S.A. e BRF S.A.) nas três operações mencionadas. Essas empresas divulgaram de 2010 a 2017, conjuntamente, 56 relatórios de guidance, incluindo as projeções e acompanhamentos.

A escolha do relatório em questão e o método de análise é justificada pelo conteúdo do relatório. O relatório de guidance apresenta as premissas, a metodologia de cálculo e publica o acompanhamento dos desvios das estimativas (Instrução n n $^{4} 80 / 2009$, CVM) feitas anteriormente pela empresa. Tal conteúdo privilegia informações qualitativas e explicativas em sua composição, e portanto a escolha de palavras, a forma de apresentação do texto, tabelas ou destaque a determinados temas escolhidos pelas empresas podem alterar o sentido e direcionar a interpretação dos stakeholders sobre o relatório contábil (Brennan, Guillamon-Saorin e Pierce, 2009). Os efeitos intencionais dessa discricionariedade pelas empresas é a essência do que é tratado pela literatura de gerenciamento de impressões.

Nesse sentido, empresas gerenciam o conteúdo dos seus relatórios de guidance na comunicação com o mercado financeiro intencionalmente para influenciar os stakeholders (Brennan \& Merkl-Davies, 2013). Os investidores seriam afetados por esta estratégia ao utilizarem tais relatórios de projeção e acompanhamento como um meio de comunicação neutro com o mercado financeiro. Além do alerta aos usuários desse relatório, a pesquisa oferece à literatura a análise do relatório de guidance como uma narrativa contábil intencional pelas organizações, e como tal gerenciamento de impressões se comporta frente às investigações que ganham repercussão pública.

\section{GERENCIAMENTO DE IMPRESSÕES}

O fenômeno 'gerenciamento de impressões' pode ser analisado sob diferentes perspectivas, como a econômica, psicológica, sociológica e crítica, chegando a diferentes explicações do porque ele acontece e se propaga (Brennan e Merkl-Davies, 2013, p. 34). Aqui adota-se a perspectiva econômica, em que empresas usam táticas racionalizadas para legitimar suas ações de acordo com a expectativa social.

O gerenciamento de impressões são táticas de comunicação empregadas por gestores de diversos níveis nas organizações para influenciar as percepções das partes interessadas, a fim de proteger ou melhorar a imagem da organização (Bansal \& Kistruck, 2006). Tais táticas são especialmente importantes quando as organizações enfrentam pressões sociais suscetíveis que ameaçam sua legitimidade social (Bansal \& Kistruck, 2006; Cho, Michelon, \& Patten, 2012), seja por agentes ou situações que fogem ao controle da própria organização. 
O gerenciamento de impressões tem sido estudado em uma variedade de situações organizacionais e embora a literatura de origem do assunto adote o nível individual de análise, essa abordagem também é adotada para análise organizacional (Bolino, Kacmar, Turnley, \& Gilstrap, 2008). No nível organizacional estas práticas são definidas como a divulgação de informações que visam racionalizar e legitimar, por tipos distintos de argumentos, a ocorrência de comportamentos antiéticos, de impactos negativos ou de problemas que possam prejudicar a imagem das organizações, gerentes ou funcionários (Boiral, 2016). Com isso, o gerenciamento de impressões restaura a congruência entre a imagem organizacional e as expectativas sociais, e/ou fornecer uma justificativa moral para comportamentos antiéticos (Fooks, Gilmore, Collin, Holden, \& Lee, 2013; Bansal \& Kistruck, 2006; Cho et al., 2012).

O gerenciamento de impressões enquanto estratégias de divulgação discricionária ou de opções de comunicação, são classificadas por Merkl-Davies e Brennan (2007) em cinco como categorias de escolhas ou manipulação de comunicação: (i) a facilidade de leitura e da retórica (Tom), (ii) conteúdo visual e estrutural (Ênfase), (iii) as comparações de desempenho, (iv) a divulgação do lucro (Seletividade) e (v) a atribuição de desempenho.

Especificamente em relatórios financeiros, as estratégias de gerenciamento de impressões abrangem tentativas de "controlar e manipular a impressão transmitida aos usuários de informações contábeis" (Clatworthy \& Jones, 2001, p.311), na forma de mensagens que distorcem o conteúdo e a apresentação dessas informações financeiras aos stakeholders (Merkl-Davies \& Brennan, 2007). Ou seja, as informações levadas aos documentos narrativos das empresas são selecionadas pelos gestores para enfatizar os resultados positivos e/ou ofuscar o desempenho negativo, dando uma perspectiva imprecisa dos resultados organizacionais.

Apesar do tema ser tratado em estudos de contabilidade, o foco da análise em geral é no Relatório de Administração (Clatworthy \& Jones, 2003) e nos relatórios financeiros (Aerts, 2005). Neste estudo e diante das denúncias e das investigações promovidas pelas operações da Polícia Federal espera-se que o guidance apresentado no Formulário de Referência seja afetado na construção das projeções ou no acompanhamento das metas lançadas pela empresa.

\section{OPERAÇÕES DA POLÍCIA FEDERAL: LAVA-JATO, ZELOTES E CARNE FRACA}

As operações da Lava-Jato, Zelotes e Carne Fraca conduzidas pela Polícia Federal investigaram denúncias envolvendo lavagem de dinheiro, corrupção do CARF para direcionamento de benefícios fiscais e processos, e adulteração de carnes vencidas. As denúncias envolveram empresas privadas e agentes de diferentes esferas e hierarquias do poder público. As transações, negociações e relações espúrias foram amplamente divulgadas nos noticiários brasileiros, no momento em que o país piora sua posição no Índice de Percepção da Corrupção, divulgado pela Transparência Internacional. Da 96 a posição em 2017, o Brasil caiu ao $79^{\circ}$ lugar em 2016, não conseguindo ainda avançar nas medidas capazes de combater as causas estruturais de corrupção no país.

Sob o prisma de combate à corrupção, em suas diferentes formas, a Polícia Federal tem atuado como agente interventor. A Operação Lava Jato implicou a Petrobras diretamente a partir de março de 2014. O objetivo da operação era investigar a atuação de doleiros na prática de crimes contra ao Sistema Financeiro Nacional, pautado em fraudes contratuais e pagamentos de propinas a agentes do poder público. Até 2017, foram deflagradas 37 fases dessa operação, tendo a Petrobras S.A. como centro das investigações, empreiteiras, doleiros, funcionários da estatal e partidos políticos apontados como responsáveis por fraudar licitações na realização de obras públicas. Estima-se que o pagamento indevido correspondia de 1\% a 5\% do montante total em contratos (Polícia Federal, 2018).

A operação Zelotes, por sua vez, foi deflagrada em março de 2015 e investigou as associações para sonegação fiscal junto ao CARF, que julga casos de sonegação tributária e os recursos colocados pelas empresas autuadas. Algumas empresas autuadas por sonegação atuavam junto ao CARF para reverter ou anular as multas aplicadas. Estima-se que $\mathrm{R} \$ 19,6$ bilhões beneficiaram tais empresas e deixaram de ser recolhidos aos cofres públicos (SAAD, 2016). Os valores monetários suspeitos de adulteração na operação Zelotes foram compilados por Nerry e Vasconcelos (2015), e estão sob suspeita de sonegação R\$ 2,75 bilhões (Bradesco S.A.), R\$ 261,19 milhões (Marcopolo S.A.) e R\$ 3,34 bilhões (Santander S.A.), todas listadas na Brasil Bolsa Balcão. A Marcopolo passou a ser investigada em março de 2016, Bradesco e Santander em maio do mesmo ano (Nery e Vasconcelos, 2015; Câmara dos Deputados, 2016). 
Por fim, a operação Carne Fraca trata de irregularidades operacionais em empresas do setor de alimentação com adulteração de carnes vencidas. Iniciada em 2017, a operação investigou fraudes laboratoriais no Ministério da Agricultura, Pecuária e Abastecimento (MAPA) e irregularidades cometidas por empresas quanto ao oferecimento de propinas para obter certificados de qualidade adulterados. Durante a primeira fase da operação, em março de 2017, a BRF S.A. foi investigada pelo uso de material impróprio na fabricação de alimentos.

\section{PROCEDIMENTOS METODOLÓGICOS}

A pesquisa analisa as empresas objeto de denúncia de investigação no âmbito das operações Lava Jato, Zelotes e Carne Fraca implicando as empresas em 2014, 2016 e 2017, respectivamente. Mais de 100 empresas foram denunciadas ao longo das investigações, incluindo empresas de capital fechado, e empresas listadas em bolsas nacionais e internacionais.

Analisamos as empresas de capital aberto listadas na Brasil Bolsa Balcão, investigadas em pelo menos uma das três operações e que divulgaram o relatório guidance no horizonte de 2010 a 2017. Selecionamos cinco organizações: Petrobras S.A.; Bradesco S.A.; Marcopolo S.A, Banco Santander S.A. e BRF S.A, que entre 2010 e 2017 divulgaram um total de 56 relatórios entre projeções e acompanhamentos que juntos constituem o relatório guidance. A análise foi feita no relatório de guidance de forma isolada, e desconsiderou as notas explicativas e o relatório de administração por serem complementares às demonstrações contábeis e cujas informações são utilizadas para fins distintos das divulgadas no guidance. O início em 2010 coincide com o início da divulgação desses relatórios pelas empresas junto ao Formulário de Referência emitido anualmente. Na Tabela 1 apresentamos as empresas cujos relatórios foram analisados.

Tabela 1. Amostra da pesquisa

\begin{tabular}{ccccc}
\hline Operação & Data de início & Empresas & Início das investigações & Fonte \\
\hline Lava Jato & março/2014 & Petrobras S. A. & março/2014 & MPF(2018) \\
\hline \multirow{2}{*}{ Zelotes } & março/2015 & Santander S. A. & maio/2016 & Nerry e Mascarenhas \\
& & Bradesco S. A. & maio/2016 & março/2016 \\
Carne Fraca & Marcopolo S. A. & Deputados (2016) \\
& \multirow{2}{*}{ março/2017 } & Brasil Foods S. A. (BRF) & março/2017 & Polícia Federal (2018); \\
& & & Salomão (2018) \\
\hline
\end{tabular}

Fonte: Elaborado pelos autores.

Foram analisados os itens 11.1 e 11.2 do Formulário de Referência, intitulado relatório 'guidance'. Este relatório é formado por duas partes, (i) o item $11.1 \mathrm{com}$ as estimativas e previsões traçadas pelas entidades e (ii) o item 11.2 com a descrição do acompanhamento dessas projeções relatada pela própria empresa. Como o guidance é um relatório de disclosure voluntário não há formato específico de como a informação deve ser apresentada. Desta forma, há variações quanto à quantidade, forma e tipo da informação divulgada pela empresa. Por fim, não há periodicidade na divulgação do guidance, ficando a critério da organização adotar, permanecer ou interromper esta prática. Destaca-se que a análise da mudança no guidance das empresas investigadas é importante para alertar os investidores no mercado de capitais das informações que poderiam afetar os resultados futuros dessas organizações.

Por se tratar de um relatório que visa expor e explicar as metas operacionais, financeiras e de investimentos traçadas pelas empresas, o guidance é constituído, majoritariamente, por informações qualitativas. Para realizar a análise destas informações adotou-se a lente teórica do gerenciamento de impressões no intuito de captar se houve mudança no 'tom' após o início das investigações da Polícia Federal. Para mensurar o gerenciamento de impressões adotou-se o procedimento de Brennan, Guillamon-Saorin e Pierce (2009), que elabora um indicador de gerenciamento a partir das informações qualitativas presentes nos relatórios, associando tais informações à um tom positivo ou negativo das palavras utilizadas, e também à posição (ênfase visual), repetição das palavras (estrutural), e uso de intensificadores (retórica). O procedimento foi aplicado tanto para as projeções (indicador de gerenciamento nas projeções) quanto para o acompanhamento (indicador de gerenciamento no acompanhamento).

Para compor os indicadores de gerenciamento fizemos uma Análise de Conteúdo nos relatórios com a identificação sistemática das características do texto (Jones \& Shoemaker, 1994; Smith, 2003). Seguimos os procedimentos sistematizados de Bardin (2008), incluindo a pré-análise dos relatórios, exploração do material, tratamento dos dados pela inferência, e interpretação das informações. A categorização das palavras no texto dos relatórios foi feita com auxílio do software Atlas Ti 8.0, para organizar, segregar as palavras-chave e mensurar o tom do relatório. 
Após a mensuração do tom do relatório (de projeções e de acompanhamento) comparamos o comportamento do tom dos relatórios (incluindo as dimensões de ênfase, estrutura e retórica). Conforme disposto na Tabela 1, adotou-se o ano em que as organizações passaram a serem investigadas nas operações, para segregar o período anterior e posterior às ações da Polícia Federal. Como parte integrante do Formulário de Referência, o guidance é emitido após o término de cada exercício social, portanto, as informações contidas no formulário correspondem ao ano social, entre janeiro e dezembro de cada período analisado.

\subsection{Tom do Relatório}

O tom do relatório, tanto para o relatório de projeções quanto para o de acompanhamento, é constituído pelo tom da divulgação, ênfase visual, estrutural e retórica.

No primeiro aspecto analisado, o tom é mensurado com o uso de dicionários para classificar as palavras com conotação positiva e negativa. O desafio nesta questão é a seleção do dicionário de palavras e os correspondentes tons a elas associados. O estudo de Brennan et al. (2009) traz diferentes dicionários que associam o tom das palavras-chaves de língua inglesa ao idioma português. Nesta pesquisa adotamos o dicionário proposto por Aguiar (2012), especificamente com palavras aplicáveis aos demonstrativos contábeis e financeiros no idioma português. Os textos dos relatórios guidances das empresas da amostra foram inseridos no software Atlas Ti 8.0, para associação das palavras com as categorias de palavras positivas e negativas. Durante o processo foi feita a avaliação se cada palavra listada pelo dicionário representava a referida conotação no contexto do relatório.

Já a ênfase é analisada de três maneiras: a visual, a estrutural e a retórica. A ênfase visual está associada ao posicionamento das palavras-chave na narrativa do relatório. A análise da ênfase visual mostra como o leitor pode ser influenciado pelas palavras positivas e/ou negativas, pois a disposição das palavras direciona a interpretação e a assimilação do conteúdo divulgado (Brennan et al., 2009). Para captar tal ênfase, o texto pode ser segmentado nos dois parágrafos iniciais (trecho de maior ênfase visual), nos $3^{\circ}$ e $4^{\circ}$ parágrafos (ênfase visual intermediária), e no restante do texto (menor ênfase visual).

A ênfase estrutural contempla a repetição das palavras-chave que pode tanto aumentar a compreensão dos relatórios financeiros, como também adicionar ruído ao processo de comunicação (Brennan \& Merkl-Davies, 2013). Ela foi captada pela quantidade de palavras-chave que foram repetidas no mesmo relatório. Por exemplo, no relatório de guidance da Petrobras, apresentado em 2011, a palavra-chave positiva "expansão" foi repetida duas vezes, ao se referir ao aumento nas unidades de acomodação do biodiesel e etanol, como destacado em "Atrasos na entrada em operação de novas unidades ou da expansão de capacidade em plantas existentes". Enquanto a palavra "desenvolvimento" foi retomada, no mesmo relatório, seis vezes para apresentar como o desenvolvimento da produção de petróleo e gás natural podem influenciar as projeções. Para a ênfase estrutural foram consideradas duas repetições que condizem às duas palavras repetidas.

Enquanto a ênfase retórica é feita pelo uso de intensificadores de sentido que dão ênfase às palavras-chave, e também podem alterar o sentido de um texto. Por exemplo, tanto a Petrobras quanto a Marcopolo utilizam-se desta forma de ênfase em seus relatórios de guidance. No relatório de projeções de 2011, a Petrobras apresenta que "A meta de longo prazo apresentou significativo crescimento [...]". Enquanto a Marcopolo utiliza da construção textual "Até meados de setembro de 2008, o crescimento expressivo da indústria brasileira [...]", no relatório de acompanhamento apresentado em 2011, para justificar as alterações nas projeções anteriores. Em ambos relatórios, foram identificadas a palavra-chave positiva "crescimento" que teve o sentido intensificado devido ao uso dos termos "significativo" e "expressivo". A recorrência de termos como "significativo", "expressivo", "maior" ou "menores" quando associados a palavras-chave com tom positivo (como crescimento) ou negativo (como queda ou atrasos).

O tom do relatório varia entre -1 (menor nível) e +1 (maior nível) e sua forma de mensuração está disposta na Tabela 2 que considera as ponderações para as distintas ênfases, conforme construto proposto por Brennan, Guillamon-Saorin, e Pierce (2009) . Por exemplo, a Petrobras alcançou o escore de - 0,70 para o tom do relatório de guidance em 2017. 
Tabela 2. Mensuração do tom do relatório

\begin{tabular}{|c|c|c|c|c|}
\hline Mensuração & Pesos & Positivas & Negativas & Total \\
\hline 1. Tom (positivo ou negativo) & 1,0 & & & \\
\hline \multicolumn{5}{|l|}{ 2.1 Ênfase Visual (localização no texto): } \\
\hline Maior ênfase visual & 1,0 & & & \\
\hline Ênfase visual intermediária & 0,5 & & & \\
\hline Menor ênfase visual & 0,0 & & & \\
\hline 2.2 Ênfase Estrutural (repetição) & 0,5 & & & \\
\hline 2.3 Ênfase Retórica (reforço) & 0,5 & & & \\
\hline Composição do Escore & & A & B & $\mathrm{C}$ \\
\hline Mensuração do Nível de Gerenciamento de Impressões & \multicolumn{4}{|c|}{$A-B=X / C$} \\
\hline
\end{tabular}

Fonte: Elaborado pelos autores.

Como a ênfase visual, estrutural e de retórica intensificam o tom (positivo ou negativo) presente no relatório, quando nos referimos ao tom, nos referimos ao tom em geral, decorrente de todos elementos combinados (ênfase, estrutural e retórica) afetando a percepção do leitor.

\subsection{Análise do conteúdo dos relatórios de guidance}

O número de páginas nos relatórios de projeção e acompanhamento varia entre as empresas, de 11 páginas no relatório de projeção da Petrobras em 2011, para 1 página em 2015, um ano após o início das investigações da Lava Jato (Tabela 3). No ano de 2015, a Petrobras apresentou disclosure a apenas um dos seis indicadores de produção de petróleo e gás natural divulgados nos anos anteriores. Esta redução na apresentação dos indicadores incentivou o maior desvio-padrão para este relatório (3.27) dentre a amostra de empresas analisadas.

Tabela 3. Estatística descritiva do número de páginas dos relatórios de guidance

\begin{tabular}{rccccccccc}
\hline \multirow{2}{*}{ Operação } & \multirow{2}{*}{ Empresas } & \multicolumn{4}{c}{ Projeção } & \multicolumn{5}{c}{ Acompanhamento } \\
\cline { 3 - 10 } & & Mín. & Máx. & Média & DP & Mín. & Máx. & Média & DP \\
\hline Lava Jato & Petrobras & $1 * *$ & $11^{*}$ & 6 & 3,27 & 1 & 3 & 2 & 0,76 \\
\hline \multirow{2}{*}{ Zelotes } & Bradesco & 2 & 3 & 2 & 0,46 & 2 & 5 & 4 & 1,19 \\
& Marcopolo & 1 & 2 & 1 & 0,52 & 1 & 3 & 2 & 0,71 \\
& Santander & 1 & 2 & 1 & 0,46 & 1 & 1 & 1 & 0,00 \\
\hline Carne Fraca & BRF & 1 & 4 & 2 & 1,04 & 1 & 7 & 4 & 2,85 \\
\hline
\end{tabular}

Fonte: Elaborado pelos autores.

Nota: *Em 2011. **Em 2015, após o escândalo, denotando redução de exposição.

Entre as empresas investigadas na operação Zelotes, o maior nível de informações divulgadas foi do Bradesco em 2010 e 2011 para a apresentação das metas, e em 2011 e 2012 para o acompanhamento das estimativas anteriores. A Marcopolo dedicou cerca de uma página de informações prospectivas sobre o nível de investimentos e de produção de ônibus no Brasil e no exterior, e duas páginas revendo e justificando o não cumprimento das metas. Já o Santander, apesar da limitação do tamanho do relatório, em 2011 focava estimativas de total de receitas, gastos, lucro líquido e carteira de crédito, e em 2016 passou a tratar de inadimplência, eficiência, comissões, base de clientes vinculados e ROE.

O Santander apresentou o relatório de acompanhamento, contudo não divulgou informações comparativas de guidance emitido em períodos anteriores. Desta forma, não é possível inferir o que promoveu a mudança na apresentação dos indicadores. Ressalta-se que nos períodos em que não foram apresentadas informações prospectivas ou de acompanhamento todas as empresas realizaram esta notificação nos respectivos relatórios, por isto apresentaram, no mínimo, uma página.

Envolvida na operação Carne Fraca, os relatórios de acompanhamento da BRF mais extenso (sete páginas) foram os de 2010 e 2012. Neste período, a empresa apresentou o que classificou como "destaques" da atuação da empresa nos três exercícios sociais anteriores à publicação do acompanhamento. As informações contemplam aspectos do mercado interno, externo, gestão operacional e financeira, além de estarem associadas ao cumprimento das metas em períodos anteriores. 
A classificação das palavras quanto ao tom (positivo ou negativo) é componente essencial para mensuração do tom do relatório. A construção do relatório de acompanhamento da BRF por exemplo, focou nos aspectos positivos do desempenho operacional e financeiro, como exemplo no relatório de 2012 em que se lê "Parcela importante de nosso sucesso depende de nossa aproximação com clientes e consumidores", ou ainda quando apresenta os destaques de 2011 da seguinte forma "Um ano [2010] a ser comemorado por ter sido muito intenso, desafiante e com muitas conquistas importantes".

A Tabela 4 apresenta a distribuição das palavras nos tons positivos e negativos para cada empresa, nos dois tipos de relatórios do guidance. No relatório de acompanhamento, cerca de $71 \%$ de palavras têm tom positivo, enquanto nas projeções esta proporção é de $66 \%$. Com exceção da Petrobras (60\% de palavras com tom negativo) e do Santander (50\%), os relatórios das demais empresas têm uma predominância do tom positivo. A diferença de tom positivo e negativo é menor dos relatórios de acompanhamento, parece que ficam mais realistas, contudo o padrão positivo se mantém para Bradesco, Marcopolo e BRF.

Tabela 4. Quantidade de palavras utilizadas pelas empresas nos relatórios de guidance

\begin{tabular}{|c|c|c|c|c|c|c|c|c|c|c|c|c|}
\hline \multirow{2}{*}{ Guidance } & \multicolumn{2}{|c|}{ Petrobras } & \multicolumn{2}{|c|}{ Bradesco } & \multicolumn{2}{|c|}{ Marcopolo } & \multicolumn{2}{|c|}{ Santander } & \multicolumn{2}{|c|}{ BRF } & \multicolumn{2}{|c|}{ Total } \\
\hline & $\mathrm{N}^{\mathrm{o}}$ & $\%$ & $\mathrm{~N}^{\mathrm{o}}$ & $\%$ & $\mathrm{~N}^{\circ}$ & $\%$ & $\mathrm{~N}^{0}$ & $\%$ & $\mathrm{~N}^{\mathrm{o}}$ & $\%$ & $\mathrm{~N}^{\mathrm{o}}$ & $\%$ \\
\hline \multicolumn{13}{|l|}{ Projeção } \\
\hline Positivas & 38 & 44 & 94 & 62 & 47 & 89 & 17 & 50 & 124 & 79 & 320 & 66 \\
\hline Negativas & 48 & 56 & 58 & 38 & 6 & 11 & 17 & 50 & 33 & 21 & 162 & 34 \\
\hline Total & 86 & 100 & 152 & 100 & 53 & 100 & 34 & 100 & 157 & 100 & 482 & \\
\hline \multicolumn{13}{|c|}{ Acompanhamento } \\
\hline Positivas & 12 & 31 & 75 & 54 & 151 & 72 & & & 415 & 78 & 653 & 71 \\
\hline Negativas & 27 & 69 & 63 & 46 & 59 & 28 & & & 114 & 22 & 263 & 29 \\
\hline Total & 39 & 100 & 138 & 100 & 210 & 100 & & & 529 & 100 & 916 & \\
\hline
\end{tabular}

Fonte: Elaborado pelos autores.

\section{ANÁLISE DO TOM DOS RELATÓRIOS AO LONGO DO PERÍODO}

O 'gerenciamento de impressões’ é visto como tática para preservar a imagem da organização (Bansal \& Kistruck, 2006), quando sob pressão social que ameaça a legitimidade social das empresas (Bansal \& Kistruck, 2006; Cho, Michelon, \& Patten, 2012). Os fatos ocorridos com estas organizações levaram-nas para vitrine, envolvidas em escândalos de corrupção em um momento em que o país desenvolvia um ambiente altamente crítico a estes eventos. Mercados de capitais estavam sensíveis à todas ocorrências similares. Com relação a comportamentos antiéticos de funcionários e diretores, a literatura de gerenciamento de resultados aponta que a organização buscará um alinhamento entre sua imagem e as expectativas da sociedade (Bansal \& Kistruck, 2006; Fooks, Cho et al., 2012; Gilmore, Collin, Holden, \& Lee, 2013; Boiral, 2016). Isso não seria feito apenas em informações transmitidas aos usuários de informações contábeis (Clatworthy \& Jones, 2001, p.311), mas em diversas mensagens aos stakeholders (Merkl-Davies \& Brennan, 2007).

Para as tabelas 5 e 6 a seguir, o painel A apresenta o comportamento do tom do relatório para os relatórios de projeção e de acompanhamento do guidance, no período de 2010 a 2017. O Painel B compara os períodos anterior e posterior ao ano em que se tornou público o envolvimento daquela empresa nas investigações. A Tabela 5 analisa a Petrobras, antes e depois do início das investigações iniciadas em 2014.

A Petrobras se envolveu com o desvio de recursos públicos por meio da associação com empreiteiras, doleiros, funcionários da estatal e partidos políticos. A denúncia apontou que a estruturação deste esquema iniciou dez anos antes das investigações, e envolvia agentes do governo de diversos partidos políticos. Pelas investigações da Polícia Federal (2018), bilhões de reais foram retirados da estatal através de cartel entre as empreiteiras para a realização de obras públicas, onde propinas alcançavam de $1 \%$ a $5 \%$ do montante total em contratos superfaturados. 
Tabela 5. O gerenciamento antes e depois da Operação Lava Jato

\begin{tabular}{|c|c|c|c|c|c|c|c|c|c|}
\hline \multicolumn{10}{|l|}{ Painel A } \\
\hline & \multirow{2}{*}{ Relatório } & \multicolumn{4}{|c|}{ Antes } & \multicolumn{4}{|c|}{ Depois } \\
\hline & & 2010 & 2011 & 2012 & 2013 & 2014 & 2015 & 2016 & 2017 \\
\hline \multirow{2}{*}{ Petrobras } & Projeção & $-0,18$ & $-0,10$ & 0,67 & 0,89 & 0,89 & $-0,71$ & $-0,70$ & $-0,70$ \\
\hline & Acompanhamento & $-0,79$ & $-0,83$ & 1,00 & 1,00 & 1,00 & $-0,64$ & $-0,20$ & 0,58 \\
\hline \multicolumn{10}{|l|}{ Painel B } \\
\hline & \multirow{2}{*}{ Relatório } & \multicolumn{4}{|c|}{ Antes } & \multicolumn{4}{|c|}{ Depois } \\
\hline & & Mín & Máx & Média & DP & Mín & Máx & Média & $\mathrm{DP}$ \\
\hline \multirow{2}{*}{ Petrobras } & Projeção & $-0,180$ & 0,890 & 0,320 & 0,540 & $-0,710$ & 0,890 & $-0,305$ & 0,797 \\
\hline & Acompanhamento & $-0,830$ & 1,000 & 0,095 & 1,045 & $-0,640$ & 1,000 & 0,185 & 0,741 \\
\hline
\end{tabular}

Fonte: Elaborado pelos autores.

Antes do início das investigações, o tom positivo nos relatórios de projeção e de acompanhamento foram crescendo até 2013. O gráfico 1 mostra o comportamento do tom dos relatórios da Petrobras.

Tom dos relatórios da Petrobrás (2010-2017)

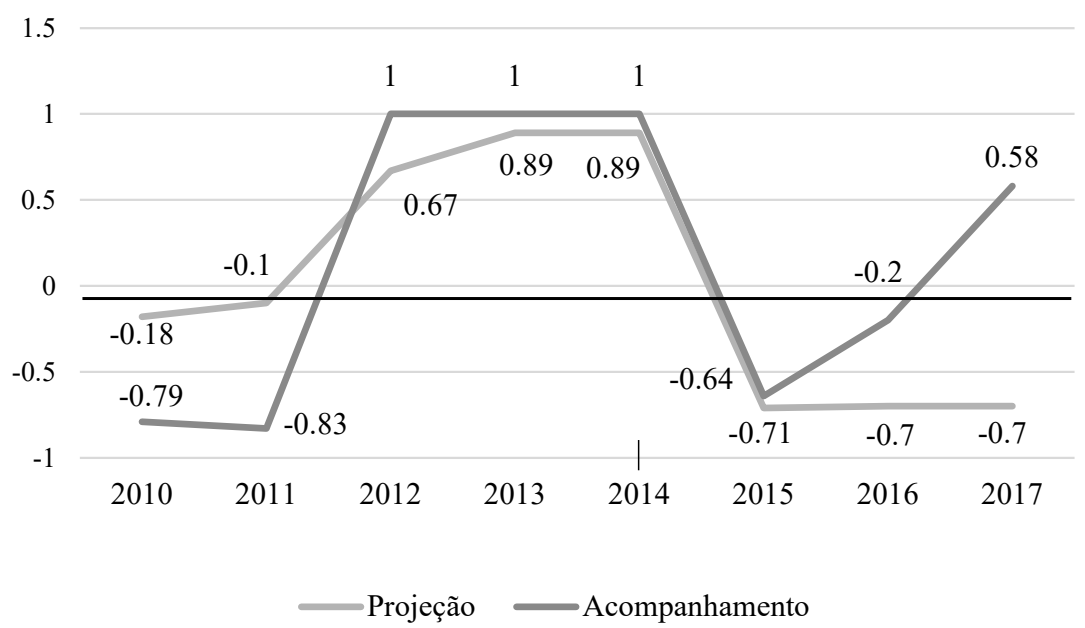

Gráfico 1. Tom dos relatórios da Petrobras (2010-2017)

Fonte: Elaborado pelos autores.

A empresa parecia bem menos otimista nos relatórios de acompanhamento de 2010 e 2011, mas o tom positivo cresceu de 2012 a 2013. A partir de 2014, quando começou a ser investigada na Lava Jato, a Petrobras reviu fortemente o tom dos seus relatórios, tanto de projeção quanto de acompanhamento. Apenas em 2017 a empresa retomou um tom mais otimista no relatório de acompanhamento.

Apesar das alterações no tom dos relatórios, a empresa não informou como a Lava Jato poderia ter ou estar alterando as projeções ou as metas traçadas em anos anteriores. A empresa contabilizou em 2014 as perdas decorrentes da operação em seus demonstrativos contábeis, com prejuízo de R 21.587 milhões, e contabilização de R $\$ 4.636$ milhões por desvalorização de ativos (impairment). Este registro teve efeitos sobre a taxa de retorno sobre o investimento que alcançou $-3,40 \%$ em 2014 frente ao resultado de $0,79 \%$ no ano anterior (Bastos, Rosa, \& Pimenta, 2016). Apesar de apresentar tais informações no relatório financeiro, a empresa não divulgou informações sobre a investigação da Lava Jato no guidance.

A Petrobras estimou uma perda de $\mathrm{R} \$ 6,1$ bilhões em contratos com empresas sob investigação (Medeiros \& Silveira, 2017). A revisão dos contratos, a perda provisionada e o desenvolvimento das investigações afetariam a elaboração e acompanhamento das informações de guidance, considerando que abrangem indicadores operacionais e de nível de investimento da empresa. 
Em 2015, foi veiculado pela mídia brasileira a redução de investimentos e desaceleração do ritmo de alguns projetos da Petrobras, assim como a venda de unidades de negócios, devido às perdas relacionadas aos esquemas de corrupção investigados pela Lava Jato (Quaino, 2015). Estas informações não foram reportadas pela empresa nos relatórios de guidance.

No relatório de projeção divulgado em 2015, o tom positivo deu lugar à um tom negativo. O número de palavras negativas foi de zero entre 2012 e 2014 para três e nove entre 2015 e 2017. O relatório foi reduzido quanto às explicações sobre as projeções. Até 2014, a empresa apresentava o objeto da projeção, as premissas e os valores estimados para seis indicadores: i) Produção de Petróleo e LGN; ii) Produção de Petróleo e Gás Natural; iii) Produção de Derivados; iv) Oferta de Gás Natural; v) Produção de Petróleo e Produção de Petróleo; e vi) Gás Natural no Exterior. A partir de 2015 a empresa optou por descrever apenas o indicador para a Produção de petróleo e LGN no Brasil em milhões de barris por dia. Isto trouxe uma redução no tom positivo do relatório, pois há menor número de palavras positivas e negativas expostas, o que afeta os intensificadores de ênfase visual, estrutura e retórica nas palavras positivas ou negativas.

Já quanto ao relatório de acompanhamento, a Petrobras retomou o tom positivo apenas em 2017, depois das investigações. Nos relatórios de 2012 a 2014, a empresa não utilizou qualquer palavra com tom negativo, levando ao máximo valor no indicador. Denota que a empresa faz uma boa avaliação das suas próprias ações de correção e ajuste de estratégia e conduta.

Na operação Zelotes, as investigações deflagradas em 2016 (Tabela 6) focaram os esquemas de sonegação fiscal junto ao CARF. O tom dos relatórios de projeção do Bradesco variou de 0,59 em 2013 a 0,03 em 2017. Era dada maior ênfase visual às palavras com tom positivo (nos parágrafos 1 e 2), com o equilíbrio do tom positivo com o negativo nestes trechos dos relatórios a partir das investigações (8 palavras para cada tom). Especificamente, o Bradesco não utilizou palavras com tom negativo nas informações prospectivas em 2014, o que destoa dos outros anos (de 10 a 6 palavras com tom negativo). As palavras negativas nos outros anos eram as que contrabalanceavam um maior número de palavras positivas, mantendo o índice razoavelmente estável até 2014.

Tabela 6. O gerenciamento para a Operação Zelotes

\begin{tabular}{|c|c|c|c|c|c|c|c|c|c|}
\hline \multicolumn{10}{|l|}{ Painel A } \\
\hline & \multirow{2}{*}{ Relatório } & \multicolumn{6}{|c|}{ Antes } & \multicolumn{2}{|c|}{ Depois } \\
\hline & & 2010 & 2011 & 2012 & 2013 & 2014 & 2015 & 2016 & 2017 \\
\hline \multirow{2}{*}{ Bradesco } & Projeção & 0,38 & 0,38 & 0,57 & 0,59 & 0,58 & 0,57 & 0,48 & 0,03 \\
\hline & Acompanhamento & 0,27 & 0,32 & 0,29 & 0,22 & $-0,11$ & $-0,35$ & $-0,29$ & $-0,33$ \\
\hline \multirow{2}{*}{ Marcopolo } & Projeção & 0,72 & 0,73 & 0,86 & 0,88 & 0,61 & - & - & - \\
\hline & Acompanhamento & 0,30 & 0,39 & 0,70 & 0,77 & 0,69 & 0,22 & 0,26 & 0,08 \\
\hline \multicolumn{10}{|l|}{ Painel B } \\
\hline & \multirow{2}{*}{ Relatório } & \multicolumn{4}{|c|}{ Antes } & \multicolumn{4}{|c|}{ Depois } \\
\hline & & Mín & Máx & Média & DP & Mín & Máx & Média & DP \\
\hline \multirow{2}{*}{ Petrobras } & Projeção & 0,380 & 0,590 & 0,512 & 0,102 & 0,030 & 0,480 & 0,255 & 0,318 \\
\hline & Acompanhamento & $-0,350$ & 0,320 & 0,107 & 0,274 & $-0,330$ & $-0,290$ & $-0,310$ & 0,028 \\
\hline \multirow{2}{*}{ Marcopolo } & Projeção & 0,610 & 0,880 & 0,760 & 0,111 & - & - & - & - \\
\hline & Acompanhamento & 0,220 & 0,770 & 0,512 & 0,236 & 0,080 & 0,260 & 0,170 & 0,127 \\
\hline
\end{tabular}

Fonte: Elaborado pelos autores.

A mesma redução no tom do relatório foi observada no relatório de acompanhamento, com maior uso de palavras com tom negativo para justificar as estimativas não realizadas. Por exemplo, usa justificativas como "retração do mercado por demanda de crédito" ao apontar um crescimento menor que o esperado para a carteira de crédito de pessoas físicas no relatório de 2015. O gráfico 2 mostra o comportamento do tom dos relatórios do Bradesco. 
Tom dos relatórios do Bradesco (2010-2017)

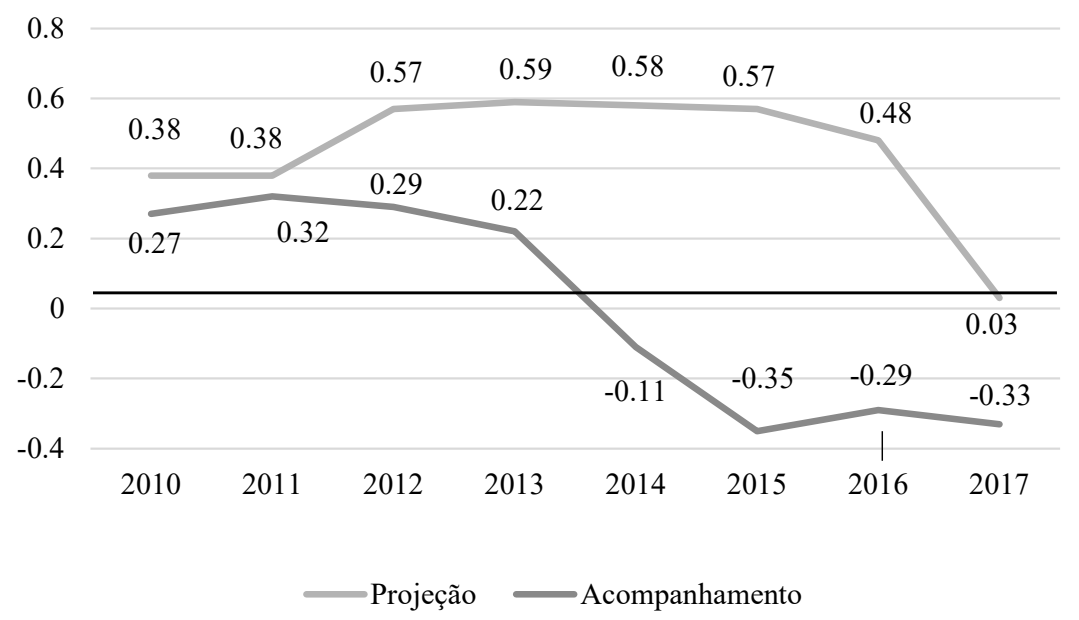

Gráfico 2. Tom dos relatórios do Bradesco (2010-2017)

Fonte: Elaborado pelos autores.

A exemplo da Petrobras, também não foram identificados apontamentos nas estimativas sobre as denúncias de investigação na correspondente operação da Polícia Federal. O relatório de 2017 divulga informações prospectivas sobre indicadores de carteira de crédito, margem financeira, prestação de serviços, despesas operacionais e prêmios de seguros. Entre os fatores externos que poderiam influenciar as estimativas são elencadas "alterações no cenário mundial" e a "política macroeconômica".

A Marcopolo, por sua vez, deixou de realizar as projeções a partir de 2015, quando a empresa informou que o adiamento da divulgação prospectiva decorreria de "indefinições econômicas e incertezas relacionadas ao setor de atuação da Companhia” (Marcopolo, 2015). Entretanto, justificativa semelhante não foi adotada por outras empresas listadas do mesmo seguimento que também divulgaram guidance no período, como Frans-Le S.A., Randon S.A. Implemenios e Participações. O gráfico 3 mostra o comportamento do tom dos relatórios da Marcopolo.

Tom dos relatórios da Marcopolo (2010-2017)

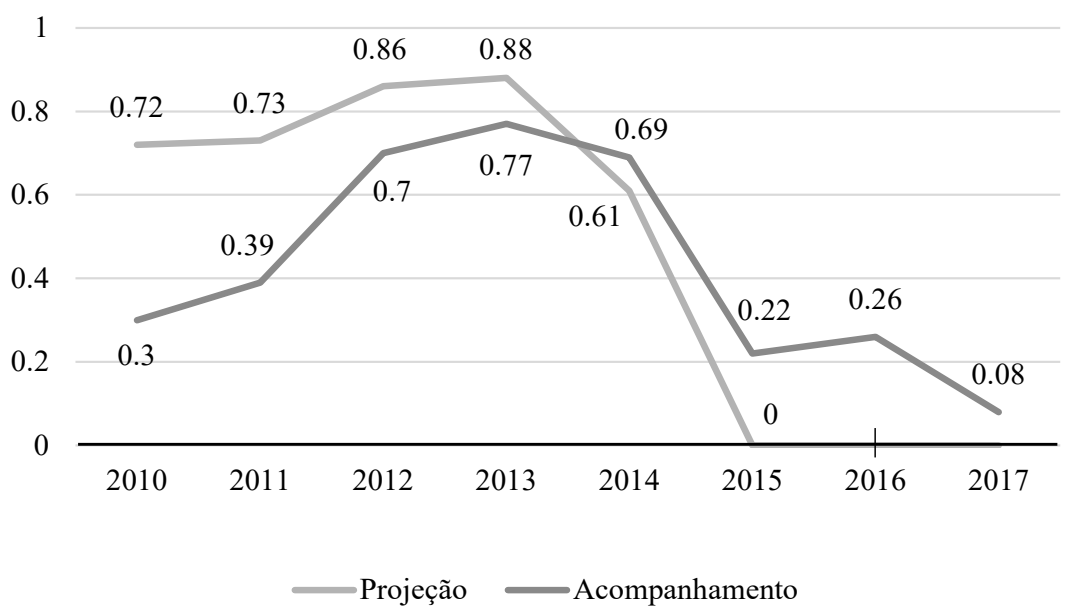

Gráfico 3. Tom dos relatórios da Marcopolo (2010-2017)

Fonte: Elaborado pelos autores. 
Para o período anterior às investigações, os relatórios de projeção divulgados pela Marcopolo usavam termos positivos contrapostos apenas com um termo negativo: "inflação", relacionada ao contexto macroeconômico, fator ambiental externo. Para o relatório de acompanhamento, a Marcopolo passou a adotar mais termos negativos a partir de 2015 para justificar o não cumprimento das metas traçadas em 2013, como a justificativa da redução nas receitas líquidas pela mudança nos veículos encomendados pelo governo do Estado do Rio de Janeiro. Ainda destaca a queda na produção em unidades da empresa no exterior, como Austrália, África do Sul e México.

$\mathrm{Na}$ análise do tom dos relatórios da Petrobras, Bradesco e Marcopolo, as operações trazem efeito na redução do tom, tanto no caso das projeções quanto no de acompanhamento, como pode ser observado nos gráficos. Mas o comportamento das 3 empresas é diferente. Enquanto Marcopolo descontinua o relatório de projeção em 2015, e o tom do relatório de acompanhamento é decrescente, o tom positivo no relatório de projeção na Petrobras se mantém e no de acompanhamento aumenta logo nos anos seguintes à denúncia.

O tom na Petrobras estava altamente positivo para ambos relatórios. Não se trata apenas de bons cenários econômicos ou produtivos, pois o indicador sobre o tom do relatório capta o uso de palavras positivas. Considerando que no ambiente competitivo e complexo que estas empresas estão sujeitas, é de se esperar que notícias e perspectivas desafiadoras também estejam presentes no cenário dessas empresas. Contudo, a escolha da divulgação foca as positivas.

Observando a variação do tom, ao longo dos anos para as diferentes empresas, todas envolvidas em escândalos, o comportamento dos indicadores mostra as escolhas de notícias ou perspectivas mais otimistas (e menos realistas) em relação aos desafios que a organização enfrenta, e portanto as projeções podem ser irrealistas ou taticamente gerenciadas.

Duas empresas envolvidas nos escândalos, a BRF (Operação Carne Fraca) e o Santander (Operação Zelotes) tiveram baixo nível de divulgação. Enquanto a BRF desde 2014 já havia deixado de relatar informações prospectivas ou de acompanhamento (Tabela 7). Já o Santander apresentou informações prospectivas nos anos de 2011 e 2016, quando apresentou um tom mais negativo, com alta repetição desses termos negativos (ênfase estrutural). As informações divulgadas em 2011 tratavam mais de crescimento financeiro (receita total, gastos, lucro líquido e carteira de crédito), já em 2016 o foco foi em eficiência, comissões pagas, base de clientes vinculados e ROE. De forma semelhante, a empresa não mencionou quaisquer dados associados à Operação Zelotes. A empresa não divulgou relatório de acompanhamento no período.

Tabela 7. Descontinuidade dos relatórios pela BRF

\begin{tabular}{|c|c|c|c|c|c|c|c|c|c|}
\hline & \multirow{2}{*}{ Relatório } & \multicolumn{7}{|c|}{ Antes } & \multirow{2}{*}{$\begin{array}{c}\text { Depois } \\
2017 \\
\end{array}$} \\
\hline & & 2010 & 2011 & 2012 & 2013 & 2014 & 2015 & 2016 & \\
\hline \multirow{2}{*}{$\mathrm{BRF}$} & Projeções & 0,68 & 0,46 & 0,61 & 0,61 & $-0,33$ & - & - & - \\
\hline & Acompanhamento & 0,37 & 0,45 & 0,56 & 0,57 & 0,67 & - & - & - \\
\hline
\end{tabular}

Fonte: Elaborado pelos autores.

Por fim, o Santander apresentou informações prospectivas (Tabela 8) nos anos de 2011 e 2016, quando apresentou um tom mais negativo, com alta repetição desses termos negativos (ênfase estrutural). As informações divulgadas em 2011 tratavam mais de crescimento financeiro (receita total, gastos, lucro líquido e carteira de crédito), já em 2016 o foco foi em eficiência, comissões pagas, base de clientes vinculados e ROE. De forma semelhante, a empresa não mencionou quaisquer dados associados à Operação Zelotes. A empresa não divulgou relatório de acompanhamento no período.

Tabela 8. Descontinuidade dos relatórios pelo Santander

\begin{tabular}{|c|c|c|c|c|c|c|c|c|c|}
\hline & \multirow{2}{*}{ Relatório } & \multicolumn{7}{|c|}{ Antes } & \multirow{2}{*}{$\begin{array}{c}\text { Depois } \\
2017\end{array}$} \\
\hline & & 2010 & 2011 & 2012 & 2013 & 2014 & 2015 & 2016 & \\
\hline \multirow{2}{*}{ Santander } & Projeções & - & 0,26 & - & - & - & - & $-0,33$ & 0 \\
\hline & Acompanhamento & - & - & - & - & - & - & - & - \\
\hline
\end{tabular}

Fonte: Elaborado pelos autores. 


\section{CONSIDERAÇÕES FINAIS}

Este artigo investigou o nível de gerenciamento de impressões pelo tom das informações prospectivas nos relatórios de guidance de cinco empresas investigadas pela Polícia Federal. Com a lente teórica do gerenciamento de impressões, a análise verificou se as investigações tiveram reflexo nas informações divulgadas entre 2010 e 2017 pela Petrobras, Bradesco, Marcopolo, Santander e BRF.

As organizações evidenciaram um tom mais positivo em seus relatórios de projeção e acompanhamento antes dos escândalos terem se tornado públicos, mesmo enquanto os fatos já estavam sendo praticados. Nos relatórios analisados, a distribuição das palavras positivas, para o relatório que contém as projeções e estimativas estão concentradas entre as regiões de maior ênfase ( $45 \%)$ e ou menor ênfase ( $43,75 \%)$ no corpo do texto do relatório, ênfase $(45 \%)$ e ou menor ênfase $(43,75 \%)$ no corpo do texto do relatório. Já no relatório de acompanhamento justificam os motivos para o não cumprimento das projeções e ressaltam os momentos de incertezas dos setores econômicos respectivos. Neste relatório, $64,17 \%$ das palavras com tom positivo são utilizadas na região de menor ênfase, ou seja, não no início do relatório. Sugerimos que estes são sinais de gerenciamento de impressões, considerando que as organizações privilegiaram a divulgação de boas notícias e restringiram o disclosure de más notícias (Brennan et al., 2009).

Em todos os casos as empresas ajustaram o tom de suas divulgações, contudo em nenhuma delas os eventos que deram origem às investigações foram tratados de forma aberta nos relatórios de acompanhamento, assim como os relatórios de projeção posteriores aos escândalos não mencionaram como as consequências financeiras e operacionais decorrentes destes fatos impactariam as projeções. No caso da Petrobras, por exemplo, as perdas registradas nos demonstrativos contábeis em 2014 relacionadas às práticas de corrupção e lavagem de dinheiro não foram tratadas. No caso da BRF o relatório já havia sido descontinuado.

A discricionariedade das empresas é alta ao divulgar informações prospectivas, tanto na escolha de quais informações divulgar, quanto no como divulgar. Isto está associado à natureza voluntária e sem uma estruturada de divulgação do guidance. As empresas têm autonomia para selecionar, classificar e apresentar informações conforme seus interesses, o que também leva à interpretação distorcida dos dados apresentados.

\section{REFERÊNCIAS}

Aerts, W. (2005). Picking up the pieces: Impression management in the retrospective attributional framing of accounting outcomes. Accounting, Organizations and Society, 30(6), 493-517. DOI: https://doi.org/10.1016/j. aos.2004.07.001

Aguiar, M. O. (2012). Sentiment Analysis em Relatórios da Administração Divulgados por Firmas Brasileiras. Dissertação de Mestrado em Administração. Fundação Instituto Capixaba de Pesquisas em Contabilidade, Economia e Finanças.

Bansal, P., \& Kistruck, G. (2006). Seeing is (not) believing: Managing the impressions of the firm's commitment to the natural environment. Journal of Business Ethics, 67(2), 165-180. DOI: https://doi.org/10.1007/s10551006-9021-9

Bastos, E. D. S., Rosa, M. P., \& Pimenta, M. M. (2016). Os Impactos da Operação Lava Jato e da Crise Internacional do Petróleo nos Retorno Anormais e Indicadores Contábeis da Petrobras 2012-2015. Pensar Contábil, 18(67), 49-56.

Bolino, M. C., Kacmar, M. K., Turnley, W. H., \& Gilstrap, B. J. (2008). A multi-level review of impression management motives and behaviors. Journal of Management, 34(6), 1080-1109. DOI: https://doi. org/10.1177/0149206308324325

Brandão, I. de F., Assunção, R. R., Ponta, V. M. R., \& Rebouças, S. M. D. P. (2013). Fatores determinantes do disclosure de guidance das companhias listadas na BM\&FBOVESPA. Revista Contemporânea de Contabilidade, 10(21), 87-114.

Brennan, Guillamon-Saorin, \& Pierce. (2009). Impression management : developing and illustrating a scheme of analysis for narrative disclosures - a methodological note. Accounting, Auditing and Accountability Journal, 22(5), 789-832.

Brennan, N., \& Merkl-Davies, D. M. (2013). Accounting Narratives and Impression Management. (L. Jack, J. Davison, \& R. Craig, Eds.). Londres: Routledge. 
Comissão de Valores Mobiliários (CVM). CVM n 480, de 07 de dezembro de 2009. Dispõe sobre o registro de emissores de valores mobiliários admitidos à negociação em mercados regulamentados de valores mobiliários. Publicado no DOU de 09/12/2009. Disponível em: http://www.cvm.gov.br/legislacao/instrucoes/inst480. html.

Cho, C. H., Laine, M., Roberts, R. W., \& Rodrigue, M. (2015). Organized hypocrisy, organizational façades, and sustainability reporting. Accounting, Organizations and Society, 40, 78-94. DOI: https://doi.org/10.1016/j. aos.2014.12.003

Cho, C. H., Michelon, G., \& Patten, D. M. (2012). Impression management in sustainability reports: An empirical investigation of the use of graphs. Accounting and the Public Interest, 12(1), 16-37. DOI: https://doi. org/10.2308/apin-10249

Clatworthy, M., \& Jones, M. J. (2001). The effect of thematic structure on the variability of annual report readability. Accounting, Auditing \& Accountability Journal, 14(3), 311-326. DOI: https://doi. org/10.1108/09513570110399890

Clatworthy, M., \& Jones, M. J. (2003). Financial reporting of good news and bad news: Evidence from accounting narratives. Accounting and Business Research, 33(3), 171-185. DOI: https://doi.org/10.1080/00014788.200 3.9729645

Fooks, G., Gilmore, A., Collin, J., Holden, C., \& Lee, K. (2013). The Limits of Corporate Social Responsibility: Techniques of Neutralization, Stakeholder Management and Political CSR. Journal of Business Ethics, 112(2), 283-299. DOI: https://doi.org/10.1007/s10551-012-1250-5

Medeiros, C. R. de O., \& Silveira, R. A. da. (2017). A Petrobrás nas teias da corrupção: mecanismos discursivos da mídia brasileira na cobertura da Operação Lava Jato. Revista de Contabilidade e Organizações, 31(34), 11-20. DOI: https://doi.org/10.11606/rco.v11i31.134817

Merkl-Davies, \& Brennan. (2007). Discretionary Disclosure Strategies in Corporate Narratives: Incremental Information or Impression Management? Journal of Accounting Literature, 26, 116-196. Retrieved from http:/hdl.handle.net/10197/2907

Ministério Público Federal - MPF (2018). Caso Lava Jato. Entenda o Caso. Recuperado de http://www. mpf.mp.br/para-o-cidadao/caso-lava-jato/entenda-o-casoNery, N., Mascarenhas, G. (2015) PF inclui Petrobras e partido PP em investigação sobre fraude fiscal. Recuperado de http://www1.folha.uol.com.br/ mercado/2015/03/1610770-pf-inclui-petrobras-e-partido-pp-em-investigacao-sobre-fraude-fiscal.shtml

Nery, N., Mascarenhas, G. (2015) PF inclui Petrobras e partido PP em investigação sobre fraude fiscal. Recuperado de http://www1.folha.uol.com.br/mercado/2015/03/1610770-pf-inclui-petrobras-e-partido-ppem-investigacao-sobre-fraude-fiscal.shtml

Polícia Federal. (2018). PF defragra fase da operação Carne Fraca. Recuperado em http://www.pf.gov.br/ agencia/noticias/2018/03/pf-deflagra-3a-fase-da-operacao-carne-fraca.

Quaino, L. (2015). Petrobras reduz investimentos e desacelera ritmo de projetos. $<$ http://g1.globo.com/economia/ negocios/noticia/2015/01/petrobras-reduz-investimentos-e-desacelera-ritmo-de-projetos.html>.

SAAD, Caio. Polícia Federal cumpre 33 mandados em nova fase da operação Zelotes. Disponível em: http:// br.reuters.com/article/domesticNews/idBRKCN0SK15R20151026.

\section{Como citar este artigo}

Arantes, V. A.; Gusmão, I. B. \& Costa, M. C. (2019). Análise do relatório de guidance em empresas investigadas pela Polícia Federal: exame sob a perspectiva do gerenciamento de impressões. Revista de Contabilidade e Organizações, 13:e148176. DOI: http://dx.doi.org/10.11606/issn.1982-6486. rco.2019.148176 